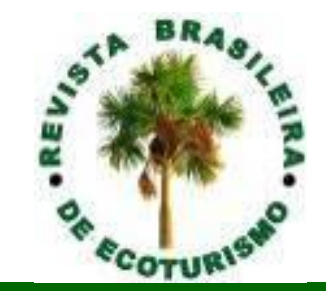

\title{
Apropriação Social nos Parques Urbanos e Naturais em Sorocaba (SP)
}

\section{Social appropriation in the Urban and Natural Parks in Sorocaba (SP, Brazil)}

\author{
Kleber Vinícius Barros Kachinsk, Maria Helena Mattos Barbosa dos Santos, \\ Eliana Cardoso-Leite
}

\begin{abstract}
RESUMO: Para conservar a natureza e garantir o uso pelas populações é essencial a existência de programas de uso público dos parques urbanos e parques naturais municipais. Para elaboração destes programas é fundamental considerar as características locais, garantindo o acesso a programas de educação não formal e de uso público de espaços públicos, mas também fomentar práticas culturais e lazer nestes espaços. Os espaços públicos são fundamentais para as cidades mais vivas, seguras, sustentáveis e saudáveis. Este trabalho aborda os parques em ambiente urbano, buscando analisar a distribuição destas áreas na cidade de Sorocaba e como se dá o uso do espaço público pela população, por meio de práticas recreativas e de lazer. O estudo de caráter exploratório, descritivo, pautado em abordagem qualitativa-quantitava, foi realizado por meio da combinação da pesquisa bibliográfica, documental e da pesquisa de campo, balizada por observação sistemática (protocolo de observação) e realização de entrevistas semiestruturadas, com os usuários dos parques urbanos e parques naturais municipais do município. Estas pesquisas foram realizadas em 8 parques da cidade. Os resultados apontam que há disparidades na oferta de serviços com relação à política de atividades e ao quesito segurança, bem como demanda por melhorias da infraestrutura e paisagismo ambiental. Os parques, são utilizados para a prática de esportes, para o descanso, encontro com amigos, passeios com crianças e contemplação da natureza. Há em Sorocaba parques em piores condições que acabam sendo subutilizados em detrimento de parques mais bem localizados e com maior concentração de renda no entorno. Os resultados suportam ações para uma intervenção mais assertiva das instituições, no que se refere à devida valorização das atividades de cultura e lazer, inclusive àquelas destinadas ao fomento da preservação e conservação ambiental.
\end{abstract}

PALAVRAS-CHAVE: Uso Público; Lazer; Meio Ambiente; Áreas Protegidas, Áreas Verdes. 
ABSTRACT: ABSTRACT: Public spaces are essential for livelier, safer, sustainable and healthier cities. It is essential the existence of public use programs for urban parks and municipal natural parks, for conserving nature and guaranteeing its use by populations. It is essential to consider the local characteristics, for the elaboration of these programs, guaranteeing access to non-formal education programs and public use of public spaces, but also to promote cultural and leisure practices in these spaces. This work addresses parks in an urban environment, seeking to analyze the distribution of these areas in the city of Sorocaba and how public space is used by the population, through recreational and leisure practices. The exploratory, descriptive study, based on a qualitativequantitative approach, it was carried out through a combination of bibliographic, documentary and field research, guided by systematic observation (observation protocol) and semi-structured interviews with users of urban parks and municipal natural parks in the municipality. These surveys were carried out in 8 parks in the city. The results show that there are disparities in the provision of services in relation to the policy of activities and the issue of security, as well as the demand for improvements in infrastructure and environmental landscaping. The parks are used for the practice of sports, for resting, meeting friends, walking with children and contemplating nature. There are parks in Sorocaba in worse conditions that end up being underutilized to the detriment of parks that are better located and with a greater concentration of income in the surroundings.

KEYWORDS: Public Use; Leisure; Environment; Protected Areas, Green Areas.

\section{Introdução}

As áreas verdes e os parques urbanos têm relevante importância e profunda relação com esferas de atuação e interesse humano (REZENDE; DALMACIO; ANNA, 2019). Para Ferreira (2005) e Dantas (2016) as áreas verdes contribuem para qualidade ecológico-ambiental (capacidade de redução dos materiais tóxicos) e qualidade de vida da população por desempenharem um papel estético (pode-se considerar o que se refere ao belo, formoso) e de lazer (ao descanso, ócio ou passatempo). A oferta de áreas livres verdes, praças, parques urbanos, zoológicos, jardins botânicos, unidades de conservação e entre outros se caracterizam como espaços fundamentais para a vida em sociedade (LONDE; MENDES, 2014; SEIXAS, 2015). Portanto, é importante trazer à superfície a discussão sobre os benefícios proporcionados por áreas verdes (naturais) ao meio ambiente e para a população concentrada em ambientes urbanos.

Outro fator destacado é o uso destas áreas como elementos de dinamização da economia urbana, em especial as atividades ligadas ao lazer (FERREIRA, 2005; PARK; KIM, 2019; SIM 2020). Neste contexto, a oferta de áreas livres verdes se caracteriza como espaços fundamentais para a vida em sociedade. Os parques urbanos em função da possibilidade de usos diversos para o lazer, são capazes de proporcionar todos os benefícios ambientais, sociais, físicos e psicológicos (EVERSON et al., 2016; PAULA, 2017).

No Brasil os primeiros grandes espaços verdes surgiram no século XVIII (PRIORE, 2016). A partir de profundas transformações das cidades brasileiras no século XIX novos espaços foram sendo criados, tendo nos parques e áreas verdes o símbolo de uma nova urbanização (PAULA, 2017). Considerando-se que a partir dos anos 70 do século XX grande parte da população brasileira vive em áreas urbanas, o consequente crescimento das cidades mostrou como a 
ação humana pode alterar os espaços e as paisagens. $O$ acelerado crescimento das cidades contribuiu para a segregação e fragmentação dos espaços públicos e limitou o acesso e o uso quantitativo e qualitativo da produção cultural e ao lazer (MELO; LOPES; SAMPAIO, 2017).

A compreensão dos aspectos espaciais, compreendidos por ruas, avenidas, praças e parques hoje segregados e fragmentados, é fundamental para a interpretação do lazer no meio urbano. Atualmente, praças e parques estão, em diferentes lugares, condenados ao esquecimento e destinados apenas para vias de circulação (ROLNIK, 2000; BURGOS, 2015a). Entretanto, Jacobs (2011) anota que as cidades podem e devem fomentar o convívio em espaços públicos. Sendo as cidades organizadas para propor lugares qualificados, viabilizando uma maior coletividade (LEFEBVRE, 2011). Entendendo os espaços públicos como fundamentais para as cidades mais vivas, seguras, sustentáveis e saudáveis (GEHL, 2013).

O lazer é um fenômeno moderno que surgiu do processo da industrialização, ou seja, um fenômeno marcadamente urbano (LEFEBVRE, 2011). A industrialização alterou não só as condições político-econômicas, mas o tempo social que passou a ser considerado um tempo linear, ou seja, modificando as relações humanas mostrando que o trabalho industrial "criou tempos" ou seja, o tempo de trabalho e o de não trabalho. Os princípios capitalistas na Idade Moderna moldam a cultura burguesa, a qual se articulam manifestações artísticas, filosóficas e científicas. Tendo na ideologia capitalista, o trabalho como elemento central para o enobrecimento e enriquecimento e trabalho e condenando o ócio e fruição (LEFEBVRE, 2011).

Assim, o fenômeno do lazer ocorre no tempo de não trabalho, ou seja, tempo liberado das obrigações profissionais, políticas, religiosas, sociais e familiares. Para Camargo (2016, p. 77):

Não há como fugir à evidência de que as condições de lazer são basicamente limitadas pelas condições de trabalho, não apenas do ponto de vista da quantidade de tempo, como de sua qualidade socioeconômica ou do consumo que nela acontece.

Portanto, neste trabalho, o lazer é abordado a partir do advento da criação da máquina, cenário que alterou o tempo e o espaço (DOMINGUES; RECHIA, 2016). Como estudado por Cunningham (2016), o lazer tem sua origem histórica com a Revolução Industrial, podendo ser entendido como uma dialética entre o fenômeno e a sociedade que o criou, manifestando-se, desta forma como questionador e ao mesmo tempo sendo influenciado pelo sistema vigente (MARCELLINO; STOPPA, 2000; DOMINGUES; RECHIA, 2016).

Nesta sociedade marcadamente industrial e moderna, o trabalho, o lazer e o tempo devem ser conceituados e interpretados para um melhor entendimento, a fim de evitar equívocos. Segundo De Grazia (1966):

O trabalho é o antônimo de tempo livre. Mas não do lazer. O lazer e o tempo livre vivem em dois mundos diferentes. Acostumamo-nos a pensar que são o mesmo, mas todo mundo pode ter tempo livre, e nem todos podem ter lazer. O tempo livre é uma ideia da democracia realizável; o lazer não é totalmente 
realizável, e, portanto, é um ideal e não só uma ideia. O tempo livre se refere a uma forma determinada de calcular uma determinada classe de tempo; o lazer é uma forma de ser, uma condição do homem, que poucos desejam e menos alcançam (DE GRAZIA, 1966, p. xix).

Neste contexto, não podemos falar de lazer sem discutir o tempo e a atitude, pois os estudos apontam que estes não devem ser considerados isoladamente. Deste modo, o que caracteriza o lazer é combinação dos aspectos tempo e atitude (MARCELLINO, 1996). O aspecto tempo relaciona-se às vivências desenvolvidas no chamado tempo livre das obrigações, sejam estas as profissionais, familiares, sociais, religiosas ou políticas (MARCELLINO, 1996). Assim, é possível discutir que o lazer em nossa sociedade advém de um tempo liberado do trabalho e das obrigações, caracterizando-se desta forma, como uma construção social

Já a atitude é o comportamento do indivíduo em relação às vivências desenvolvidas em seu tempo de lazer, sem a característica da obrigação encontrada em outras esferas da vida (MARCELLINO, 1996). Além disso, caracteriza esse aspecto a liberdade de escolha em relação às vivências de lazer, com destaque para as possibilidades de descanso, divertimento e desenvolvimento pessoal e social (DUMAZEDIER, 1980). Assim, de acordo com Dumazedier (1980) o lazer é um conjunto de atividades não obrigatórias em que o indivíduo se entrega de livre escolha, criando e alterando aspectos sociais e pessoais e ainda, pode criar situações de divertimento, recreação ou descanso.

Através do processo de formação destes centros urbano-industriais, a vida urbana passou a congregar relações entre cidade e o campo. Assim, parques, jardins e águas cativas passam a ganhar simbolismos únicos de natureza inseridos no urbano (LEFEBVRE, 2011). Autores como Jacobi (2005) Pacheco e Raimundo (2014) e Dantas (2016) apontam para as mais diversas questões e interpretações da sociedade em relação à natureza e por meio do fomento da educação ambiental e das políticas públicas de uso público nos parques urbanos e parques naturais municipais é possível ofertar as pessoas, " 0 palco dos acontecimentos, das manifestações, das novas ideias, promovendo assim o direito à cidade" (SILVA; PASQUALETTO, 2013, p. 296).

No entanto, as interações nos espaços públicos não estão livres das referências históricas, culturais e das estratificações sociais ou de classes de uma sociedade (SÁNCHEZ; MARTÍNEZ, 2021). Portanto, verifica-se que é importante planejar e criar parques urbanos e parques naturais municipais, além de implantar programas de Uso Público, com vistas não apenas à correção da carência de espaços públicos naturais, mas também, à democratização do uso e apropriação da população de espaços coletivos e da cidade (JACOBS, 2011; LONDE E MENDES, 2014). Assim, Sakata (2018, p.338) analisa:

Programas de uso acertados e bons projetos paisagísticos são absolutamente necessários. Eles viabilizam os arranjos que tornam possíveis os parques, tornam possíveis a execução e a manutenção de melhor qualidade e estão na base da apropriação dos espaços pelas pessoas. Projetos de parques que valorizam a cidade sem seu entorno tornam duradoura 0 investimento feito no espaço público 
Reforçando que no Brasil, a Constituição Federal de 1988 constitui como um instrumento político determinante para defesa destes direitos sociais e ambientais. Com a nova Constituição, o lazer e o meio ambiente equilibrado são reconhecidos como direitos dos cidadãos. Concluindo que o entendimento de meio ambiente e lazer colocados ao longo deste trabalho são compreendidos e refletidos como esferas de atuação humana que contribuem para efetivo desenvolvimento dos indivíduos (GUTIERREZ, 1998; STOPPA, 2005).

Seguindo esta dinâmica nacional de crescimento econômico das zonas urbanizadas, a cidade de Sorocaba e a região metropolitana na qual a cidade está inserida sofrem acelerada expansão da sua atividade industrial e de sua zona urbana. Segundo Priore (2016) a cidade é marcadamente complexa e passou por um acelerado desenvolvimento ao longo das últimas décadas com a vinda de muitas indústrias multinacionais, universidades e empresas prestadoras de serviços. Todo este elevado potencial econômico estimulou o crescimento da sua população e consequentemente da sua área urbana, alterando e refletindo nas áreas verdes da cidade.

\section{Material e Métodos}

\section{Caracterização da área de estudo}

A cidade Sorocaba, localizada a sudeste do estado de São Paulo, a 90 km da capital paulista, com uma população estimada pelo IBGE (BRASIL, 2021) de aproximadamente 695.000 habitantes, tem um dos maiores Índice de Desenvolvimento Humano (IDH) do Brasil, com 0,798. A região metropolitana de Sorocaba ${ }^{1}$ conta com aproximadamente 2 milhões de pessoas e é responsável por 3\% do Produto Interno Bruto Estadual (PIB), que em termos totais corresponde à 35 , bilhões de reais, a partir dos dados averiguados pela Fundação Sistema Estadual de Análise de Dados (SEAD, 2021).

Sorocaba é responsável por quase $50 \%$ do PIB produzido dentro da RMS (Região Metropolitana de Sorocaba), $11^{\circ}$ no ranking estadual de receitas produzidas, resultados que, alicerçados no desenvolvimento da indústria, do comércio e dos serviços (há mais 22 mil empresas instaladas) e na exportação de sua produção industrial para mais de 120 países, alçam a cidade à posição de $5^{\underline{a}}$ cidade em desenvolvimento econômico do Estado de São Paulo (SEAD, 2021).

Mello (2016) estudando áreas prioritárias para conservação mapeou todos os fragmentos florestais do município de Sorocaba, e registrou a ocorrência de 2537 fragmentos, sendo 67\% deles de tamanho igual ou menor que 1 ha. Segundo a autora (MELLO, 2016) os maiores fragmentos não estão localizados em áreas públicas. Este estudo também destacou a necessidade de restauração da vegetação nativa das margens dos cursos d'água e ao redor das nascentes.

Motta (2016) analisou as áreas denominadas parques (áreas livres e áreas protegidas) também em Sorocaba. O autor registrou a ocorrência de 33 áreas, sendo que 5 foram consideradas como Unidades de Conservação, 9 como áreas de transição, denominadas pelo autor de AIAs (áreas de interesse ambiental), e 19 foram identificadas como ELUPIS (espaços livres de uso público e interesse social). 
O autor conclui que Sorocaba apresenta espaços livres para uso da população, no entanto, a maioria destes espaços não cumpre o papel de conservação dos recursos naturais, sendo mais utilizados para lazer e recreação. A cidade de Sorocaba tem oferta de áreas verdes em seu território e estas são importantes para a qualidade de vida da população (LONDE; MENDES, 2014), além de a cidade gozar de boa condição econômica para investimentos em ações e políticas públicas.

Assim, o presente trabalho traz como proposta, avançar nos estudos sobre os parques urbanos e parques naturais municipais de Sorocaba e o uso público destes espaços pela sociedade. As perguntas que nortearam este artigo são: A população se apropria destes espaços para lazer e recreação? Há programas de Uso Público referente a estas áreas no município? Os parques são igualmente equipados e conservados pelo poder público?

O estudo de caráter exploratório, descritivo, pautado em abordagem qualiquanti, por meio da combinação de levantamento bibliográfico, análise documental e pesquisa de campo (SEVERINO, 2000), foi balizada por observação sistemática (suportada por protocolo de observação) nos parques urbanos e parques naturais municipais do município de Sorocaba-SP.

As técnicas, entendidas como "procedimentos mais restritos que operacionalizam os métodos, mediante emprego de instrumentos adequados" (SEVERINO, 2000, p. 162) foram:

\section{A análise documental}

Foi realizada mediante o levantamento dos documentos consultados da Secretaria de Meio Ambiente (SEMA) através Área de Serviços Urbanos Divisão de parques - que propiciou a identificação dos parques existentes e suas características catalogadas no ano de 2018. A Tabela 1 demonstra as informações do local, região e tamanho dos 33 parques catalogados. Os parques que não estão com a identificação da área (ha) são devido à falta deste dado na tabela oferecida pela SEMA.

Quadro 1: Localização por região, bairro e tamanho dos Parques da cidade de Sorocaba/SP. As áreas com * são UCs reconhecidas pelo SNUC.

Framework 1: Location by region, neighborhood, and size of the Parks of the city of Sorocaba / SP. Areas with * are UCs recognized by the SNUC.

\begin{tabular}{|c|c|c|c|c|}
\hline LEGENDA & Nome do Parque & BAIRRO & $\begin{array}{l}\text { ÁREA } \\
\text { (ha) }{ }^{\star *}\end{array}$ & ZONA \\
\hline 1 & Parque Chico Mendes & Alto da Boa Vista & 14,50 & Leste \\
\hline 2 & Parque do Paço Municipal de Sorocaba & Alto da Boa Vista & 21,80 & Leste \\
\hline 3 & Parque Yves Ota & $\begin{array}{l}\text { Jd. Iguatemi/Vila } \\
\text { Morumbi }\end{array}$ & & Leste \\
\hline 4 & Parque Steve Paul Jobs & Jd. Bandeirantes & & Leste \\
\hline 5 & $\begin{array}{l}\text { Parque Linear Armando Pannunzio - Av. Dom } \\
\text { Aguirre. }\end{array}$ & Abaeté & 25,00 & Leste \\
\hline 6 & $\begin{array}{c}\text { Jardim Botânico de Sorocaba Irmãos Villas - } \\
\text { Bôas }\end{array}$ & Jd. Dois Corações & 19,20 & Leste \\
\hline 7 & Parque Porto das Águas & Jardim Iguatemi & & Leste \\
\hline
\end{tabular}

Continua... 


\begin{tabular}{|c|c|c|c|c|}
\hline LEGENDA & Nome do Parque & BAIRRO & $\begin{array}{r}\text { ÁREA } \\
\text { (ha)** }\end{array}$ & ZONA \\
\hline 8 & Parque Das Águas & Jd. Abaeté & 16,20 & Leste \\
\hline 9 & Parque Dr. Bráulio Guedes da Silva & Além Linha & 8,87 & Leste \\
\hline 10 & Parque Quinzinho de Barros Zoológico & VI. Hortência & 12,87 & Leste \\
\hline 11 & Parque dos Espanhóis & Parada do Alto & 2,00 & Sul \\
\hline 12 & Parque da Biquinha & Emília & 2,77 & Sul \\
\hline 13 & Parque Kasato Maru & Campolim & 0,90 & Sul \\
\hline 14 & Parque Campolim & Campolim & 7,40 & Sul \\
\hline 15 & Parque da Água Vermelha & Jd. Europa & 2,70 & Sul \\
\hline 17 & Parque João Pellegrini & Central Parque & 1,73 & Oeste \\
\hline 18 & Parque Antônio Latorre & Jd. Arco Iris & 4,40 & Oeste \\
\hline 19 & Parque Maestro Nílson Lombardi & Jd. Ipiranga & 6,20 & Oeste \\
\hline 20 & Parque Santa Bárbara & $\begin{array}{l}\text { CH. Júlio de } \\
\text { Mesquita Filho }\end{array}$ & 17,30 & Oeste \\
\hline 21 & Parque Ouro Fino & Pq. Ouro Fino & 9,68 & Oeste \\
\hline 22 & Parque Walter Grillo & Lopes de Oliveira & 1,53 & Oeste \\
\hline 23 & $\begin{array}{c}\text { Parque - Sist. Lazer Amália Helena Bertelle } \\
\text { Camargo }\end{array}$ & Pq. São Bento & 1,30 & Norte \\
\hline 24 & Parque Santi Pegoretti & Jd. Maria Eugênia & 8,93 & Norte \\
\hline 25 & $\begin{array}{r}\text { Parque Natural Municipal } \\
\text { Corredores da } \\
\text { Biodiversidade* }^{*}\end{array}$ & Itavuvú & 62,42 & Norte \\
\hline 26 & Parque da Formosa & VI. Formosa & 20,00 & Norte \\
\hline 27 & Parque Ant. Amaro Mendes & Brasilândia & & Norte \\
\hline 28 & Parque Amedeo Franciulli - Vitória Régia & Pq. Vitória Régia & 24,00 & Norte \\
\hline 29 & $\begin{array}{c}\text { Parque Rubens Cernomoret - Est. } \\
\text { Tratamento de Água } \\
\text { ETA Éden }\end{array}$ & Éden & 1,30 & Norte \\
\hline 30 & Parque Natural Municipal Pirajibu* & Éden & 45,00 & Norte \\
\hline 31 & Estação Ecológica Governador Mário Covas* & Cajurú & 50,07 & Norte \\
\hline 32 & $\begin{array}{c}\text { Sist. De Lazer - Parque Raul de Moura } \\
\text { Bittencourt }\end{array}$ & Villa Amato & & Leste \\
\hline 33 & $\begin{array}{c}\text { Parque Natural Municipal de Brigadeiro } \\
\text { Tobias* }\end{array}$ & Passa Três & 1,56 & Leste \\
\hline
\end{tabular}

** Parques que não possuem a identificação da área (ha) explicitam a ausência deste dado na tabela oferecida pela SEMA. Fonte: Elaboração própria, 2017. Source: Own elaboration, 2017.

A partir da Tabela 1 foram selecionadas as áreas estudadas a partir do conjunto de parques existentes. Seguindo os critérios físicos e ambientais (tamanho, cobertura vegetal), de acesso ao público (com ou sem cerca) e de localização (distribuídas nas diferentes regiões da cidade). A análise da distribuição espacial dos PU (Parques Urbanos) e PNM (Parques Naturais Municipais) foi realizada mediante a localização das áreas de estudo utilizandose a ferramenta Google Maps, análise primária cruzada com dados de localização de análises realizadas por Reis (2015) que também contemplaram o 
estudo da densidade populacional das diferentes regiões da cidade de Sorocaba/SP. A Figura 1 representa o mapeamento dos parques com destaque, em amarelo, para os parques abordados neste trabalho.

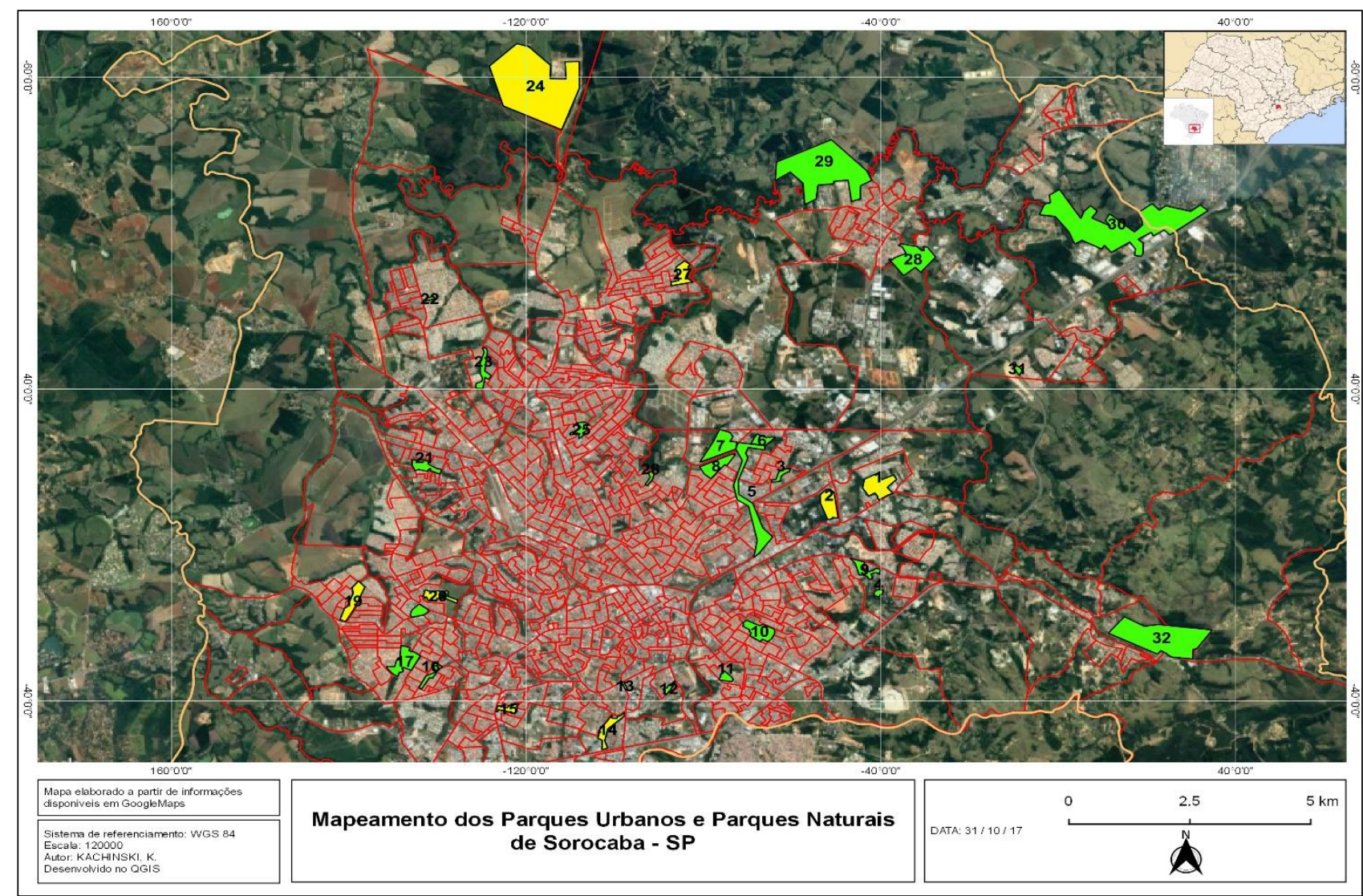

Figura 1: Parques Urbanos e Parques Naturais de Sorocaba/SP, 2017. Em verde total de parques, em amarelo parques analisados neste estudo.

Figure 1: Urban Parks and Natural Parks of Sorocaba / SP, 2017. Green are all parks, yellow show the parks analised in present study.

Fonte: Kachinski (2017). Dados cartográficos 2017 - Google Imagens.

Source: Kachinski (2017). Map data 2017 - Google Images.

Sendo assim, foram selecionados dois grupos de áreas: grupo 1representado por áreas com maior cobertura vegetal (com objetivo mais focado na conservação) e grupo 2- representado por áreas com menor cobertura vegetal (com objetivo mais focado no lazer/eventos). Ou seja, o primeiro grupo inclui os denominados pelo município de "parques naturais" e uma Unidade de Conservação, e o segundo grupo inclui os "parques urbanos". Ambos os grupos com áreas presentes em diferentes regiões da cidade. Considerando o grupo 1 foram selecionados: (1) Parque Chico Mendes (Leste), (20) Parque Ouro Fino (Oeste), (15) Parque da Água Vermelha (Sul) e (24) PNM Corredores Da Biodiversidade (Norte). Considerando o grupo 2, foram selecionados: (14) Parque Campolim (Sul), (2) Parque do Paço Municipal (Leste), (19) Parque Santa Barbara (Oeste) e (27) Parque Amedeo Franciulli - Vitória Régia (Norte). Dos 8 parques 7 estão localizados em áreas urbanizadas, apenas o PNMCBio está localizado em área com entorno rural (Figura 1). 


\section{Pesquisa de Campo}

O principal instrumento de coleta de dados foi a observação simples (BRUYNE; HERMAN; SCHOUTHEETE, 1977), pressupondo observação direta, com a utilização de diário de campo, procedimento realizado nos parques. Como forma de aprofundar a pesquisa exploratória, foi utilizada a metodologia proposta por Triviños (2008) em que foram realizadas entrevistas junto aos visitantes. A abordagem é quantitativa e a definição da amostra se deu de forma probabilística, não intencional, para a população que utiliza os parques da cidade (BRUYNE; HERMAN; SCHOUTHEETE, 1977). Sendo a pesquisa realizada aos finais de semana, por meio de roteiros semiestruturados, na área amostral (oito parques selecionados).

Em cada área (8 parques selecionados) foi despendido em torno de 2 horas de trabalho de campo - entrevistas com visitantes/usuários, no período da manhã ou das tardes de final de semana (sábado e domingo) do ano de 2018. Somente para a área, Unidade de Conservação Corredores da Biodiversidade, a visita e as entrevistas não foram realizadas no domingo, pois a unidade não abre aos domingos. Neste sentido, não foi estipulado quantidade mínima de pessoas para entrevistas, mas sim realizado o máximo de entrevistas no tempo de permanência no parque.

No total foram coletadas 181 entrevistas com os visitantes dos PU e PNM. Após o levantamento dos dados em campo, estes foram tabulados no software Excel, posteriormente tratados e analisados utilizando da ferramenta "Tabela dinâmica" do Excel. O roteiro de perguntas utilizado está descrito a seguir:

1-Você mora em Sorocaba? Em qual bairro?; 2-Teve dificuldades de acesso? Qual o meio de transporte utilizado?; 3-Você costuma vir aqui com qual frequência?; (1 x mês, 1 x sem); qual o dia da semana? 4-Que atividades costuma desenvolver aqui? (Caminhada, bicicleta, pic nic, ouvir música, encontrar amigos etc.); 5-Existem outras áreas como este parque perto de sua residência? Você costuma frequentá-la também?; 6-Que nota você daria para esta área (Qualidade para o meio ambiente, lazer e recreação) - 0 a 10; 7-Que aspectos você considera negativos nesta área?; 8-O que você gostaria que mudasse, melhorasse nesta área?; 9-Se melhorasse (mudasse) você viria aqui com mais frequência?

\section{Resultados e Discussão}

Todo o potencial de crescimento da cidade de Sorocaba, estimulou o aumento da sua população e consequentemente a influência da sua área urbanizada, e que por fim altera e reflete nas áreas verdes da cidade (CELLI, 2012; COMITRE, 2017). Devido ao intenso uso do território e dos elementos ambientais, a cobertura vegetal do município de Sorocaba encontra-se reduzida e distribuída em pontos isolados, com um forte desmatamento do centro para as regiões periféricas, com poucas regiões conservadas de mata.

No momento da coleta foram catalogados 33 espaços verdes públicos do município de Sorocaba sob a denominação de parques, conforme a legislação municipal de acordo com a Área de Serviços Urbanos (ASU) da Divisão de Parques (DPAR) da Secretaria do Meio Ambiente (SEMA). Deste montante, 25 foram instituídos após a criação do SNUC, no ano 2000 e, entre as Unidades de 
Conservação (UC) sorocabanas estão a Estação Ecológica "Governador Mário Covas", localizada no Cajuru; a Estação Ecológica do Pirajibu e o Parque Natural Municipal de Brigadeiro Tobias, criados em 2015, bem como o Parque Natural Municipal Corredores de Biodiversidade, inaugurado em 2013 (MANFREDINI; GUANDIQUE E ROSA, 2015).

Como abordado por Kachinski, Santos e Cardoso-Liete (2018) há oferta de PU em todas as regiões da cidade, e de PNM apenas nas regiões norte e leste. O total da soma da extensão territorial dos parques de Sorocaba compreende uma área de 374,7 ha, sendo que o parque com menor área, denominado Parque Margarida Leão Camargo - possui uma área de 0,6711 ha e o maior, a Unidade de Conservação "PNM Corredores da Biodiversidade", na zona norte, compreende uma área de 62,42 ha. Destes parques, 4 são Unidades de Conservação (UC), ou seja, estão incorporados ao Sistema Nacional de Unidades de Conservação da Natureza (SNUC) e à Lei 11.073 que instituiu o Sistema Municipal de Áreas Protegidas, Parques e Espaços Livres de Uso Público. O Parque Natural Municipal Corredores da Biodiversidade, o Parque Natural Municipal Pirajibu e a Estação Ecológica Mário Covas, todos localizados na zona norte, são UCs, assim como Parque Natural Municipal de Brigadeiro Tobias, instalado na zona leste.

As duas regiões que mais possuem metros quadrados ou hectares em parques são a região leste, que possui 12 parques, totalizando 120,01 ha, dos quais 1 é UC, e a região norte, que possui 6 parques urbanos e 3 parques naturais municipais (UCs Gov. Mario Covas, Corredores da Biodiversidade e Pirajibu) que são prioritárias para preservação e conservação da natureza. Estas 9 áreas totalizam 158,30 ha e apresenta-se como relevante na questão da conservação de áreas naturais, pois apresenta as maiores concentrações de domicílios particulares permanentes e atendem a uma grande concentração de pessoas (KACHINSKI; SANTOS; CARDOSO-LEITE, 2018). Já a zona sul, dispõe de 5 parques; é a região com menor número de parques, que totalizam 15,77 ha. A zona oeste, por fim, possui 6 parques, totalizando 40.

Em relação à política e gestão de parques urbanos, Sorocaba pode ser comparada com outras cidades como Juiz de Fora em Minas Gerais (PAULA; FERREIRA, 2014). Sorocaba conta com uma maior distribuição dos parques em relação a Juiz de Fora, e em ambas as cidades os parques com melhor infraestrutura e bem equipados ficam em regiões de maior renda.

De acordo com Reis (2015) e Burgos (2015b) entre a distribuição de parques e a distribuição de renda do município pode-se observar que as maiores rendas estão nas regiões sul e leste, porém a distribuição dos parques se dá em toda extensão de área do município, estando ausente apenas na região central da cidade.

No total foram coletadas 181 entrevistas, os dados mostraram que $90 \%$ dos entrevistados residiam em Sorocaba, e somente $10 \%$ residiam em outros municípios da RMS. Os informantes destacam que as opções de parques oferecidos por Sorocaba são melhores e maiores em relação as suas cidades. De certa forma os números de entrevistados refletem o fluxo de visitação aos finais de semana. Parques como: Parque Ouro Fino na zona oeste e PNM Corredores da Biodiversidade, zona norte, foram os lugares com menor visitação observada. 
A maioria dos entrevistados (55,8 \%) dos entrevistados relatou visitar os parques aos finais de semana ( 1 vez por final de semana). Não foi registrada qualquer tipo de dificuldade no acesso, sendo citado o "automóvel" (50\% dos entrevistados) como principal meio de transporte para acessar as áreas. Há um número proporcional entre os usuários que afirmam ter áreas próximas a suas residências e os usuários que afirmam não haver áreas desta natureza. Conforme Figura 1, há um número elevado de parques e estão presentes em todas as regiões da cidade.

A Tabela 2 demonstra os visitantes que apontaram possuir parques próximos e os que indicaram não ter parques próximos à residência.

Tabela 2: Respostas dos entrevistados para a questão: "Existem outras áreas como este parque perto de sua residência? Você costuma frequentá-la também?

Table 2: Answers about the question: "Are there other areas like this parks near your home? Do you usually visit this park?

\begin{tabular}{|l|c|c|c|c|c|c|}
\hline \multicolumn{1}{|c|}{ Nome } & Zona & $\begin{array}{c}\text { Há parques } \\
\text { próximos a } \\
\text { residência }\end{array}$ & $\begin{array}{c}\text { Não há } \\
\text { parques } \\
\text { próximos a } \\
\text { residência }\end{array}$ & Frequenta & $\begin{array}{c}\text { Não } \\
\text { Não } \\
\text { frequenta }\end{array}$ & $\begin{array}{c}\text { opinaram ou } \\
\text { não } \\
\text { souberam } \\
\text { opinar }\end{array}$ \\
\hline Pq. Campolim & Sul & 12 & 18 & 6 & 6 & - \\
\hline Pq. Água Vermelha & Sul & 11 & 19 & 6 & 5 & 5 \\
\hline $\begin{array}{l}\text { Pq. do Paço } \\
\text { Municipal }\end{array}$ & Leste & 23 & 10 & 10 & 16 & - \\
\hline Pq. Chico Mendes & Leste & 13 & 17 & 11 & 2 & - \\
\hline $\begin{array}{l}\text { Pq. do Vitória } \\
\text { Régia }\end{array}$ & Norte & 10 & 5 & 5 & 5 & - \\
\hline PNMCBio & Norte & 4 & 3 & 4 & - & - \\
\hline Pq. Santa Bárbara & Oeste & 15 & 10 & 6 & 9 & - \\
\hline Pq. Ouro Fino & Oeste & - & 6 & - & - & - \\
\hline Total Geral & & 88 & 88 & 48 & 43 & 5 \\
\hline
\end{tabular}

Do total $49 \%$ dos entrevistados registraram a inexistêcias de parques próximos a suas residências (Tabela 2), outros $49 \%$ indicaram existir áreas como parques próximos as suas residências, embora tenham mencionado não frequentar estes espaços e $2 \%$ não opinaram.

Foi perguntado "Qual a sua motivação em vir visitar este parque?" nesta abordagem não foi delimitado a quantidade de respostas e os visitantes responderam mais de uma motivação para visitar os parques. As entrevistas realizadas apontam que em $41 \%$ das respostas, o principal motivo para visitação é o passeio (individual ou em grupo) e $24 \%$ destacaram o passeio feito com crianças.

Algumas destas áreas possuem características para o uso das crianças, como o Parque do Paço e Água Vermelha, os quais possuem maior oferta de brinquedos. Porém muitos dos espaços utilizados pelas crianças não são destinados e adequados para o público infantil, uma vez que foi observado a utilização das academias ao ar livre instaladas nestes parques como "brinquedos" (Figura 2). 


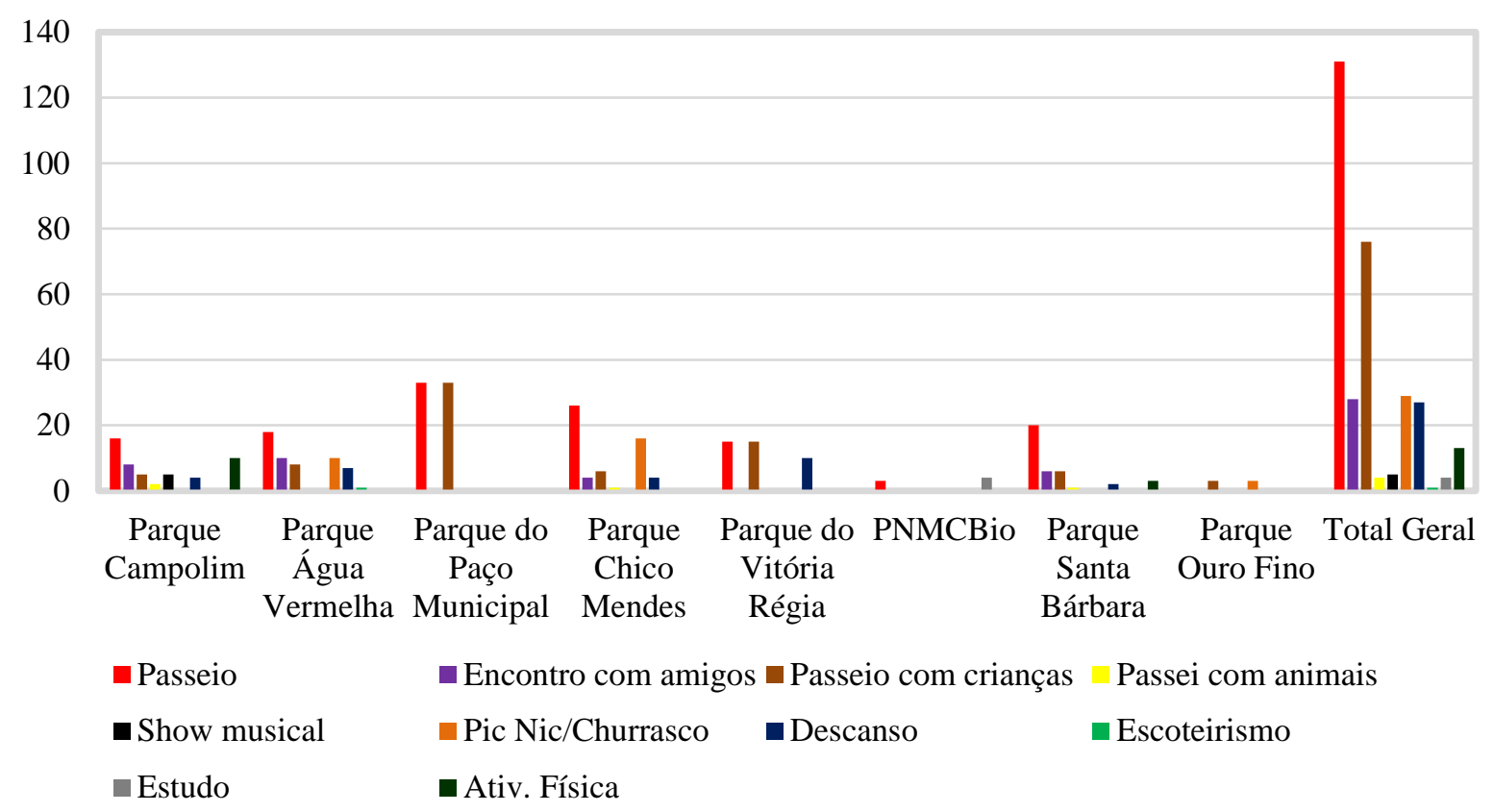

Figura 2: Respostas dos entrevistados para a questão: "Qual a sua motivação em vir visitar este parque?" Figure 2: Answers about the question:" What's your motivation to visit this park?"

Fonte: Elaboração própria, (2018).

Source: Own elaboration, (2018).

Outras motivações para visitar os parques foram "o encontro com os amigos" com 9\% das respostas e "fazer pic nic ou churrasco" em 9\%, ou seja, formas de convivência social, com ou sem alimentação. Foram observadas e atribuídas diferentes funções a estes parques, em geral os parques naturais tendem a receber pessoas que buscam contemplação e convívio com a natureza, dando destaque para o que Dumazedier (1980) chamou de aspecto de descanso do lazer. O descanso também foi citado, em menor proporção $(8 \%)$ e as demais motivações como "assistir a shows" em $2 \%$ das respostas a "realização de práticas esportivas" com $4 \%$.

Os parques Chico Mendes e Campolim foram os que apresentaram maior diversidade de respostas, tais como fazer churrasco, pic nic, leitura, plantio de árvores e passeio com animais de estimação. Alguns parques como "Parque Campolim" e "Vitória Régia" foram registradas predominância de práticas esportivas. No primeiro (Campolim) onde foram observados grupos de corredores e de caminhada, praticantes de ioga, slackline, ciclistas e entre outros. No segundo (Vitória Régia) foram observados jogos de futebol que ocorrem aos finais de semana. O parque Vitória Régia é o único que possui equipamentos para idosos, chamado de "parque do idoso".

Pode-se observar que os Parques do grupo 1 - Parque Campolim (Sul), Parque do Paço Municipal (Leste), Parque Santa Barbara (Oeste) e Parque Vitória Régia (Norte) - possuem pista de caminhada, campos de futebol e academia ao ar livre, assim contemplando o conteúdo cultural físico esportivo do lazer, características que lhe conferem destaque como equipamento específico de função esportiva. Outro ponto de destaque nestes equipamentos são os fragmentos de áreas verdes que passaram por um processo de tratamento paisagístico, o que compreende cuidados de conservação, estéticos e 
estruturais com a área, como por exemplo, corte do gramado, poda das árvores, arborização e manutenção das calçadas.

Os Parques do grupo 2- Chico Mendes (Leste), Ouro Fino (Oeste), da Água Vermelha (Sul) e PNM - Corredores Da Biodiversidade (Norte), possuem maior cobertura florestal, além de trilhas, quiosques, espaços de convivência, brinquedos e áreas para atividades de recreação e educação, cumprindo a função para a qual foram criados, tanto do ponto de vista da conservação, quanto do lazer e da recreação.

Assim, como na abordagem sobre o que motiva os visitantes, quando questionados sobre os aspectos negativos dos Parques não foi delimitado a quantidade de respostas e os visitantes puderem destacar mais de um aspecto negativo. Com maior frequência foram citados aspectos de abandono em 14\% das respostas (para todas as regiões, exceto zona sul), "falta de conservação" com $22 \%$ e $18 \%$ destacaram o "gramado alto" agrupados como "conservação/manejo" refletindo assim, necessidade de atenção por parte do poder público para com a manutenção destas áreas (Tabela 3).

Tabela 3: Respostas dos entrevistados para a questão: "Que aspectos você considera negativos neste Parque?"

Table 3: Answers about the question: "What aspects do you consider negative in this Park?"

\begin{tabular}{|l|c|c|c|c|c|c|c|c|c|c|}
\hline \multicolumn{1}{|c|}{ Nome } & Zona & $\begin{array}{c}\text { Aban } \\
\text { dono }\end{array}$ & $\begin{array}{c}\text { Bebidas } \\
\text { e drogas }\end{array}$ & $\begin{array}{c}\text { Falta } \\
\text { de } \\
\text { segur } \\
\text { ança }\end{array}$ & $\begin{array}{c}\text { Falt } \\
\text { a de } \\
\text { árvo } \\
\text { res }\end{array}$ & $\begin{array}{c}\text { Árvores } \\
\text { mortas/re } \\
\text { ssecadas }\end{array}$ & $\begin{array}{c}\text { Gram } \\
\text { a/mat } \\
\text { o alto }\end{array}$ & $\begin{array}{c}\text { Lixo/ } \\
\text { Falta } \\
\text { lixeira }\end{array}$ & $\begin{array}{c}\text { Falta de } \\
\text { Conserva } \\
\text { ção }\end{array}$ & $\begin{array}{c}\text { Falta } \\
\text { de } \\
\text { ativid } \\
\text { ades }\end{array}$ \\
\hline Pq. Campolim & Sul & - & 1 & 5 & 3 & 3 & 3 & 3 & 12 & 3 \\
\hline $\begin{array}{l}\text { Pq. Água } \\
\text { Vermelha }\end{array}$ & Sul & - & 9 & 8 & - & - & 3 & - & 3 & 1 \\
\hline $\begin{array}{l}\text { Pq. do Paço } \\
\text { Municipal }\end{array}$ & Leste & 3 & - & - & - & - & 26 & - & 3 & 1 \\
\hline $\begin{array}{l}\text { Pq. Chico } \\
\text { Mendes }\end{array}$ & Leste & 3 & - & - & 4 & - & - & - & 10 & 10 \\
\hline $\begin{array}{l}\text { Pq. Vitória } \\
\text { Régia }\end{array}$ & Norte & 15 & 15 & 15 & - & - & - & 15 & 15 & - \\
\hline PNMCBio & Norte & - & - & - & - & - & - & - & - & 7 \\
\hline $\begin{array}{l}\text { Pq. Santa } \\
\text { Bárbara }\end{array}$ & Oeste & 15 & 2 & 8 & - & - & 14 & - & 14 & 8 \\
\hline Pq. Ouro Fino & Oeste & 6 & 3 & - & - & - & 6 & - & 6 & 6 \\
\hline Total Geral & & 42 & 30 & 36 & 7 & 3 & 52 & 18 & 63 & 36 \\
\hline
\end{tabular}

Em segundo lugar e com mesma frequência de citação foram registrados "falta de segurança" (com maior proporção para o Parque Vitória Régia) e "falta de atividades" (principalmente para os Parques Chico Mendes e Santa Bárbara) em torno de $13 \%$ das respostas. Vale ressaltar que o Parque Vitória Régia se localiza na zona norte, região de condição socioeconômica mais precária, explicando assim, a necessidade de segurança devido a altas taxas de violência registradas nesta zona. Em terceiro lugar foi citado o problema do "uso de bebidas e drogas" nos Parques o que parece estar associado a "falta de 
segurança", principalmente nos Parques "Vitória Régia", "Água Vermelha" e "Santa Bárbara" (Tabela 3).

Os Parques Vitória Régia, zona norte e Santa Bárbara, zona oeste, ambos em zonas periféricas. São os que mais foram indicados pelos visitantes na questão da preocupação com a violência, com $64 \%$ da totalidade de respostas, nestes parques os visitantes comentaram mais vezes $(71 \%)$ sobre 0 parque estar abandonado, evidenciando sobre o uso de drogas e bebidas e outros tipos de criminalidades como tráfico de drogas, estupros e assassinatos, fatos que os deixam mais inseguros ao frequentarem estes parques. Este aspecto de abandono também relacionado ao lixo acumulado, equipamentos depredados e pouco conservados. Foi considerado também como abandono a respostas que apontaram a carência de infraestrutura, ausência de lixeiras, bebedouros, banheiros, bancos, sinalização para segurança do visitante.

As respostas relacionadas à carência de árvores para sombra, árvores ressecadas e mortas, a grama/mato alto, e o descuido com o verde e trilhas e lixo acumulado foram unificadas e categorizadas como falta de conservação e paisagismo. Considerado por $22 \%$ dos entrevistados este aspecto negativo está relacionado a todos os parques, exceto no PNMCBio.

Do ponto de vista dos visitantes, há carência de atividades para crianças, e pouca oferta de atividades culturais como shows, apresentações teatrais e musicais nos parques de Sorocaba. As respostas concordam com as observações realizadas por (KACHINSKI; SANTOS; CARDOSO-LEITE, 2018) que apontam para uma carência de programação de atividades disponibilizadas e dirigidas aos visitantes por meio das Secretarias de Cultura, de Esportes e de Meio Ambiente aos finais de semana. Assim, como observado por Kachinski (2012) as ações seguem centradas em grandes eventos, que embora importantes, são atividades pontuais realizadas em diferentes épocas do ano, como no período de férias de julho e janeiro. Contudo, a carência de atividades não é realidade em todos os parques, como descreve Burgos (2015a, p. 130):

O Parque do Campolim, como é popularmente conhecido, está plenamente inserido no contexto de valorização do seu entorno. O parque conta com eventos regulares organizados pela Secretaria Municipal de Cultura, cuja curadoria define seu público-alvo, notadamente das classes médias.

Como estudado por Marcellino (1996) as políticas públicas de lazer e animação são substituídas por um calendário de eventos, fato que também ocorre em muitas cidades brasileiras. Para Marcellino (1996) os pacotes técnicos de atividades de lazer e recreação somente obedecem a um cronograma de atividades, as quais não estão contextualizadas com a realidade de cada local deste modo se pode inferir que é necessária a revisão das atuais políticas públicas de lazer, recreação, cultura e educação ambiental.

Para amenizar tal problemática é necessário haver um diálogo entre 0 poder público e sociedade, evitando o afastamento das comunidades frente ao planejamento das ações e políticas públicas de lazer e meio ambiente. Pacheco e Raimundo (2014) descrevem o programa de Uso Público contemplando: 
aspectos culturais, atividades artísticas, apresentações, festividades, oficinas que contemplem a todos.

Neste contexto, a Figura 3 demonstra as respostas para melhorias nos aspectos negativos da Tabela 3 , nesta abordagem não foi delimitado a quantidade de respostas e os visitantes puderem destacar mais de uma necessidade de melhoria.

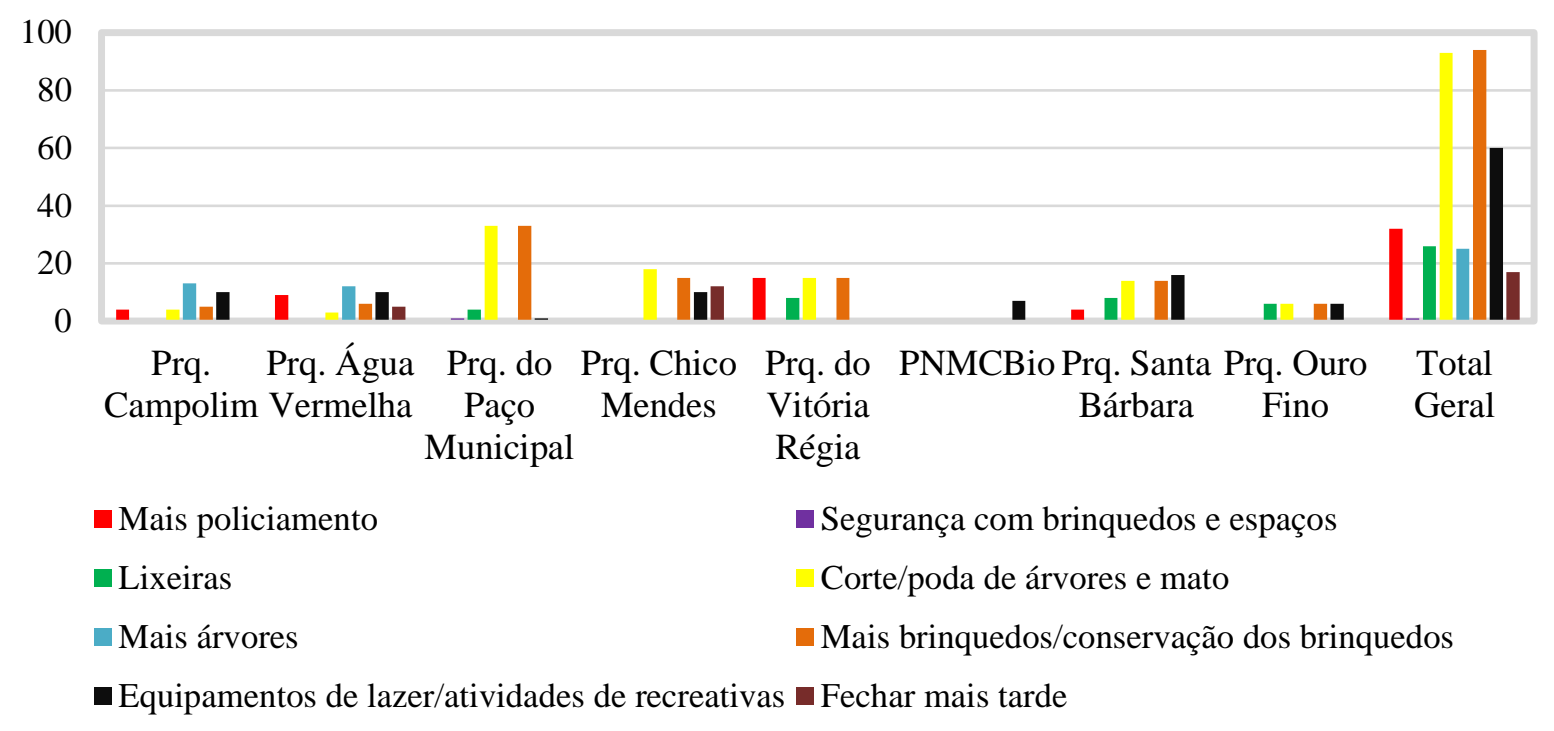

Figura 3: Respostas dos entrevistados para a questão: "O que você gostaria que mudasse, melhorasse nesta área?"

Figure 3: Answers about the question: "What would you like to change, improve in this area?"

Fonte: Elaboração própria, (2018).

Source: Own elaboration, (2018).

Quando questionados sobre as melhorias necessárias nas áreas analisadas (Figura 3) a conservação dos equipamentos, mais lixeiras, poda de árvores e corte da grama são os aspectos mais citados (34\% dos entrevistados). Do total $28 \%$ dos entrevistados indicaram necessidade de melhorais nos equipamentos ou estrutura para lazer direcionados para as crianças, e em seguida $17 \%$ dos entrevistados solicitaram mais atividades de lazer/recreação. Ainda $9 \%$ dos entrevistados a necessidade de maior policiamento, com destaque para as respostas no Parque Vitória Régia, e 7\% gostariam de parques mais arborizadas. Finalizando com $4 \%$ dos entrevistados apontaram a necessidade de aumento no horário de funcionamento, dos parques fechados. Desta forma, o uso está intimamente relacionado a solicitação de melhoras e maiores cuidados com o paisagismo dos parques, a instalação de equipamentos recreativos, em geral, brinquedos para as crianças e melhorias com os já existentes como aquários, manutenção dos campos, das academias ao ar livre e com os quiosques, e com relação a segurança destas áreas.

Portanto, foi observado em campo, nos parques do Paço e Chico Mendes brinquedos interditados, por questões de segurança aos usuários. Além dos equipamentos a ação pública não contempla atividades recreativas dirigidas com uma oferta de profissionais capacitados para atender a população. Os visitantes entrevistados apesar de elencarem pontos negativos e sugerirem melhoras dão altas notas, para a maioria dos parques, com relação a qualidade da conservação, ao lazer e a recreação (Tabela 4). 
Tabela 4: Respostas dos entrevistados para a questão: "Que nota você daria para esta área (qualidade para o meio ambiente, lazer e recreação) - 0 a 10"

Table 4: Answers about the question: "What grade would you give to this area (quality for the environment, leisure and recreation) - 0 to 10"

\begin{tabular}{|l|c|c|c|c|c|c|c|c|c|}
\hline \multicolumn{1}{|c|}{ Nome } & Zona & Nota 10 & Nota 9 & Nota 8 & Nota 7 & Nota 6 & Nota 5 & Nota 3 & Média \\
\hline Pq. Campolim & Sul & 10 & 12 & 8 & - & - & - & - & 9,06 \\
\hline Pq. Água Vermelha & Sul & 13 & 6 & 12 & 1 & 1 & 3 & - & 8,8 \\
\hline Pq. do Paço Municipal & Leste & 7 & - & 1 & 9 & 5 & 11 & - & 6,84 \\
\hline Pq. Chico Mendes & Leste & 13 & 5 & 9 & - & 3 & - & - & 8,83 \\
\hline Pq. do Vitória Régia & Norte & - & 8 & 5 & 2 & - & - & - & 8,4 \\
\hline PNMCBio & Norte & - & 2 & 5 & - & - & - & - & 8,28 \\
\hline Pq. Santa Bárbara & Oeste & 8 & - & 8 & 1 & 5 & 1 & 2 & 7,68 \\
\hline Pq. Ouro Fino & Oeste & - & - & - & 3 & 3 & - & - & 6,5 \\
\hline
\end{tabular}

A nota atribuída pelos visitantes com relação as atividades de lazer e recreação e ao parque como um todo refletem estas diferenças entre os parques e a disfunção de políticas públicas de meio ambiente, lazer e cultura da cidade. Os parques que receberam a melhor média de notas 9,06 e 8,83 Campolim e Chico Mendes respectivamente são os que menos foram apontados com relação ao abandono, falta de segurança e uso de bebidas e drogas (Figura 3) e conforme exposto por Reis (2015), Burgos (2015b) e Machado-Hess (2020) são regiões com as melhores médias de renda. O parque Vitória Régia, apesar de ter sido o mais destacado com relação ao uso de bebidas e drogas, a necessidade de mais segurança, recebeu uma boa média de nota com 8,4, ou seja, apesar dos problemas as pessoas gostam e frequentam o Parque Vitória Régia. As menores notas foram dadas aos Parques do Paço e Ouro Fino.

Portanto muitos visitantes buscam além do descanso e brinquedos para crianças, mais atividades culturais, guias nas trilhas, espaços mais arborizados e com árvores frutíferas, e atividades recreativas dirigidas por profissionais. A Tabela 5 apresenta os resultados sobre a frequência de visitas e possível aumento na frequência caso houvesse melhorias nos parques. Pode observar (Tabela 5) que 52\% dos entrevistados afirmaram que visitaria a área com mais frequência, se as melhorias fossem implementadas, como exemplo o Parque Ouro Fino.

Tabela 5: Respostas dos entrevistados para a questão: "Se melhorasse (mudasse) você viria aqui com mais frequência?"

Table 5: Answers about the question: "If it got better (changed) would you come here more often?"

\begin{tabular}{|l|c|c|c|c|c|}
\hline \multicolumn{1}{|c|}{ Nome } & Zona & Indiferente & $\operatorname{Sim}$ & Não & $\begin{array}{c}\text { Não opinarão ou não } \\
\text { souberam opinar }\end{array}$ \\
\hline Parque Campolim & Sul & 10 & 8 & 3 & 9 \\
\hline Parque Água Vermelha & Sul & 16 & 14 & - & 4 \\
\hline Parque do Paço Municipal & Leste & - & 1 & 32 & - \\
\hline Parque Chico Mendes & Leste & 11 & 17 & - & 2 \\
\hline Parque do Vitória Régia & Norte & - & 15 & - & - \\
\hline Parque PNMCBio & Norte & - & 7 & - & - \\
\hline Parque Santa Bárbara & Oeste & 2 & 23 & - & 1 \\
\hline Parque Ouro Fino & Oeste & - & 6 & - & - \\
\hline Total Geral & & 39 & 91 & 35 & 16 \\
\hline
\end{tabular}


As respostas retratam que as ações públicas podem contribuir para mudar a frequência de visitas. Portanto, tais aspectos devem ser entendidos como objeto de ação do poder público por meio de um planejamento e políticas públicas específicas para a área, contribuindo para o desenvolvimento da cidadania das pessoas. Neste contexto, quanto melhor a qualidade dos serviços ofertados mais a população identifica se com o espaço e o uso é mais intenso como registrado por Faustino e Teles (2021). Além do mais pode se inferir que a partir das abordagens realizadas por Kachinski, Santos e Cardoso-Leite (2018) os parques localizados em regiões com renda mais elevada, são os que possuem infraestrutura, conservação, paisagismo, segurança e a oferta de atividades é maior, como também registrado por outros autores (MACHADO-HESS, 2020). Estes parques foram os mais bem avaliados (Tabela 4).

\section{Considerações Finais}

De maneira geral os parques estão distribuídos em toda a cidade, no entanto, nas regiões norte e leste apresentam um maior número de parques. A concentração destes não está relacionada às características de renda das regiões.

Os resultados mostram também que os parques mais bem avaliados nos quesitos infraestrutura, manutenção e segurança estão nas regiões onde a população apresenta maior renda (região sul) e são mais frequentemente visitados, em evidência os Parques Campolim, Água Vermelha, ambos na zonal sul e Chico Mendes, zona leste que recebem visitantes de todas as zonas de Sorocaba.

Pode-se concluir também que Sorocaba apresenta alguns parques em piores condições localizados ou em regiões com menor renda (zonas norte e oeste). Estes parques não contam com a devida atenção do poder público, em seus aspectos de conservação, paisagismo e de infraestrutura, sendo também os mais citados entre os entrevistados em relação a preocupação com segurança.

Concluindo que as áreas verdes (parques urbanos e parques naturais municipais) da cidade devem ganhar maior atenção para sua conservação e utilização, a partir de um programa de Uso Público, pois são importantes espaços para defesa da natureza e a vida em sociedade. Por outro lado, a sociedade como um todo, por meio de ações individuais e coletivas, em conjunto com governo, entidades privadas e o terceiro setor, devem provocar questionamentos acerca da ordem social estabelecida, contribuindo para a superação do status quo e para a construção de uma cidade mais justa e com mais consciência a respeito da conservação da natureza.

Embora longe de concluir o assunto, entende-se que o estudo pode colaborar para o entendimento de como o sorocabano, se apropria e usa os parques, suas relações com a natureza e os anseios por melhoras. Subsidiando novas reflexões acerca das características de lazer, recreação e cultura da população, bem como propiciar novas ações para o poder público e outras instituições ressaltando seu compromisso com a instauração de uma sociedade mais justa e participativa. 


\section{Referências}

BRASIL. Senado Federal. Constituição da República Federativa do Brasil. Brasília: Centro gráfico - Senado Federal, 1988.

BRASIL: Instituto Brasileiro de Geografia e Estatística - IBGE. Pesquisa de Informações Básicas Municipais: Perfil dos Municípios Brasileiros. 2021. Acessado em: <https://biblioteca.ibge.gov.br/visualizacao/livros/liv101595.pdf> em 01 de dez. de 2021.

BRUYNE, P; HERMAN, J; SCHOUTHEETE, M. de. Dinâmica da pesquisa em ciências sociais. Rio de Janeiro: Francisco Alves, 1977.

BURGOS, R. Espaços públicos e o direito à cidade: contribuições teóricoconceituais a partir de estudos sobre o uso de parques urbanos em contextos de segregação espacial nas cidades de São Paulo e Sorocaba. Revista Cidades - Leitura Sobre a Cidade, v. 12, n. 20, 2015a.

BURGOS, R. Pesquisa qualitativa: reflexões geográficas a partir de um estudo de caso sobre as contradições urbanas da cidade de Sorocaba - SP. Geographia Meridionalis, v. 01, n. 01, pág. 145-159, Jun/2015b.

CAMARGO. L. O. L. O lazer e a ludicidade do brasileiro. In: SESC SP. (Org.). Revista do Centro de Pesquisa e Formação, n.2, maio/2016. SESC, p.76-29.

CELLI, A. Evolução Urbana de Sorocaba. 2012. 130f. Dissertação (Mestrado) em Planejamento Urbano e Regional (FAUUSP), Univ. de São Paulo, 2012.

COMITRE, F. A evolução do uso e ocupação do solo na periferia urbana de Sorocaba-SP: do esquecimento ao despertar dos interesses públicos e privado. Geo, UERJ, Rio de Janeiro, n. 31, p. 770 -799, 2017.

CUNNINGHAM, H. Leisure in the Industrial Revolution c. 1780-c. 1880. London: Routledge, 2016. 213 p.

DANTAS, M.K. Análise da gestão ambiental no Estado de São Paulo: Programa município Verde-Azul, gastos públicos e indicadores de saúde. Ribeirão Preto, 2016. 211p. Faculdade de Economia, Administração e Contabilidade - Ribeirão Preto/USP.

DE GRAZIA, S. Tiempo, trabajo y ócio. Madrid: Tecnos, 1966.

DOMINGUES, T. RECHIA, S. Trabalho e lazer: Oposição ou composição? Licere, v. 19 n. 3 (2016): setembro.

DUMAZEDIER, J. Valores e conteúdos culturais do lazer. São Paulo: SESC, 1980.

EVENSON, K. R. et al. Park characteristics, use, and physical activity: a review of studies using SOPARC (System for Observing Play and Recreation in Communities). Preventive Medicine, n. 86, 2016, p. 153-166.

FAUSTINO, D. U. REINALDO, M. Sá. de. Pesquisa de satisfação em parques urbanos: um estudo no Parque Ibirapuera (SP). Revista Brasileira de Ecoturismo, São Paulo, v. 14. n. 3. ago-out 2021, pp. 391-416.

FERNANDES, A. C. T. D. Metodologias de Avaliação da Qualidade dos Espaços Públicos. Dissertação (Mestrado em Arquitetura Paisagística) - Universidade Técnica de Lisboa, Lisboa, 2012. 
FERREIRA, A. D. Efeitos positivos gerados pelos parques urbanos: $O$ caso do passeio público da cidade do Rio de Janeiro. 2005. 99f. Dissertação (Mestrado) Programa (PGCA) - Universidade Federal Fluminense. Rio de Janeiro, 2005.

SEAD- Fundação Sistema Estadual de Análise de Dados. Disponível em: <http://www.imp.seade.gov.br/frontend/> acessado em 01 de Julho de 2021.

GEHL, J. Cidades para pessoas: tradução Anita Di Marco - 2 ed. São Paulo: Perspectiva, 2013.

GEHL, J. SVARRE, B. How to study public life. Editora Sland Press, 2013.

GUTIERREZ G. L. Lazer e pobreza: aspectos de uma falsa questão. Conexões, v.1, n. 1, p. 28-38, 1998.

JACOBI, P. R. Educação Ambiental: o desafio da construção de um pensamento crítico, complexo e reflexivo. Educação e Pesquisa, São Paulo, v.31, n. 2, p. 233-250, maio/ago. 2005

JACOBS, J. Morte e vida de grandes cidades. São Paulo: Editora WMF Martins Fontes, 2011. - (Coleção Cidades).

KACHINSKI, K. V. B. Políticas públicas de lazer: Um estudo de caso na Secretaria de Cultura e Lazer de Sorocaba-SP. Trabalho de Conclusão de Curso - EACH/USP. São Paulo, 2012.

KACHINSKI, K. V. B; SANTOS, M. H. M. B; CARDOSO-LEITE, E. Oferta Parques Urbanos e Naturais de Sorocaba (SP): alavanca/estímulo para políticas de uso público. Revista Brasileira de Ecoturismo, São Paulo, v.11, n.3, ago/out 2018, pp.466-490.

LEFEBVRE, H. O direito a cidade. São Paulo: Editora Centauro, 5 ed. 2001. 3a reimpressão -2011.

LONDE, P. R; MENDES, P. C. A influência das áreas verdes na qualidade de vida urbana. Universidade Federal de Uberlândia. Revista Brasileira de Geografia Médica e Saúde, v. 10, n. 18, jun./2014.

MACHADO-HESS, E. S. de. Atlas escolar de Sorocaba-SP. História, Geografia e Ambiente. 2020.

MANFRADINI, F. N; GUANDIQUE, M. E. G; ROSA, A. H. A história ambiental de Sorocaba. Sorocaba: Unesp - Inst. Ciência e Tecnologia - Campus Sorocaba, 2015.

MARCELLINO, N. C.; Estudos do lazer: uma introdução. Campinas, SP: Autores Associados, 1996.

MARCELLINO, N. C.; STOPPA, E. A. Entretenimento, lazer e segurança. In: PINTO, L. M. S. M.; CASTRO, N. T. de. Coletânea $12^{\circ}$ ENAREL - Encontro Nacional de Recreação e Lazer. Balneário Camboriú: Roca, 2000, p.232-241.

MELO, H.M.S; LOPES, W.G.R; SAMPAIO, D.B. Os Parques Urbanos na História da Cidade: percepção, afetividade, imagem e memória da paisagem. Revista Nacional de Gerenciamento de Cidades - ANAP, v. 05, n. 32 ano 2017.

MELLO, K.; TOPPA, R.H; CARDOSO-LEITE, E., 2016. Priority areas for forest conservation in an urban landscape at the transition between Atlantic forest and cerrado. Cerne, v.22, n.3, p.277-288. 
MOTA, M.T. et. al. Categorização da infraestrutura verde do município de Sorocaba (SP) para criação de um sistema municipal integrando espaços livres e áreas protegidas. Revista Brasileira de Ciências Ambientais, n. 41, p.122140, set. 2016.

PACHECO, R. T. B; RAIMUNDO, S. Parques urbanos e campos dos estudos do lazer: propostas para uma agenda de pesquisa. Rev. Brasileira de Estudos do Lazer. Belo Horizonte, v. 1, n. 3, p. 43-66, set./dez. 2014. Dossiê Lazer e Meio Ambiente.

PAULA, D. Usos e desusos de parques urbanos contemporâneos: estudo de caso parque da cidade - Serra/ES. Dissertação (Mestrado) - Universidade Federal do Espírito Santo. Vitória, 2017.

PAULA, I. F. M. de; FERREIRA, C. C. M d. Análise dos espaços de uso público da cidade de juiz de fora $(\mathrm{mg})$ com base no conceito de áreas verdes. Caminhos de Geografia, v. 15, n. 49 p. 160 - 174, Mar/2014. Uberlândia 2014.

PARK, J; KIM, J. Economic impacts of a linear urban park on local businesses: The case of Gyeongui Line Forest Park in Seoul. Landscape and Urban Planning. Volume 181, January 2019, Pages 139-147.

PLANO MINICIPAL DE MATA ATLÂNTICA. Plano Municipal de conservação e Recuperação de Mata Atlântica. Sorocaba, 2014. 154 p.

PRIORE, M.D. Histórias da gente brasileira. Vol. 1: Colônia. Ed.: LeYa. São Paulo, 2016.

REZENDE, J. A; DALMACIO, F. Z; ANNA, F. P. S. Características determinantes no desempenho ambiental dos municípios paulistas. Revista de Administração Pública. Rio de Janeiro, v.53, n.2, p.392-414, mar. - abr. 2019.

REIS, R. R. G. de. Estimação do preço implícito de amenidades urbanas no município de Sorocaba. 2015. 74 f. Dissertação (Mestrado) - Centro de Ciências e Tecnologias para Sustentabilidade, Universidade Federal de São Carlos, Sorocaba, 2015.

ROLNIK, R. O lazer humaniza o espaço urbano. In: SESC SP. (Org.). Lazer numa sociedade globalizada. São Paulo: SESC. Paulo/World Leisure, 2000.

SÁNCHEZ, G. J. G. MARTíNEZ, P. M. P. La apropiación y el uso del espacio público urbano. Los comunes en el parque urbano. Economía, Sociedad y Territorio, vol. xxi, núm. 65, 2021, 57-85.

SEVERINO, A. J. Metodologia do trabalho científico. 21 $1^{\underline{a}}$ ed. São Paulo: Cortez, 2000.

STOPPA, E. A. Tá ligado mano: o hip-hop como lazer e busca da cidadania. 2005. 143f. Tese (Doutorado) - Faculdade de Educação Física. Universidade Estadual de Campinas, Campinas, 2005.

SAKATA, F. G. Parques Urbanos no Brasil - 2000 a 2017. Tese (Doutorado). Faculdade de Arquitetura e Urbanismo da Universidade de São Paulo. São Paulo, 348 p. 2018.

SEIXAS, R. A. C. Qualidade do Espaço Público: Metodologias de Avaliação. Dissertação (Mestrado) apresentada Instituto Superior de Agronomia da Universidade de Lisboa, 2015. 
SILVA, J. B; PASQUALETTO, A. O caminho dos parques urbanos brasileiros: Da origem ao século XXI. Estudos. Goiânia, v.40, n.3, p.287 - 298, jun./ago. 2013.

SIM, J. Seeing impacts of park design strategies on local economy through big data: A case study of Gyeongui Line Forest Park in Seual. Sustainability, 2020, v.12, 6722 .

TRIVIÑOS, A. N. S. Introdução à pesquisa em ciências sociais: a pesquisa qualitativa em educação. São Paulo: Atlas, 2008.

\section{Notas:}

1 Sub-região 1: Alambari, Boituva, Capela do Alto, Cerquilho, Cesário Lange, Jumirim, Sarapuí, Tatuí, Tietê e Itapetininga, município que foi incorporado à região após a sua institucionalização; Sub-região 2: Alumínio, Araçariguama, Ibiúna, Itu, Mairinque, Porto Feliz, Salto e São Roque; Sub-região 3: Araçoiaba da Serra, Iperó, Piedade, Pilar do Sul, Salto de Pirapora, São Miguel Arcanjo, Sorocaba, Tapiraí e Votorantim.

${ }^{2}$ Os autores em construção coletiva com os alunos da disciplina Uso Público em Parques Urbanos da EACH/USP criaram um roteiro de observação de parques urbanos.

Kleber Vinícius Barros Kachinsk: Universidade Federal de São Carlos, Sorocaba, SP, Brasil.

E-mail: kleber.kachinski@gmail.com

Link para o currículum Lattes: http://lattes.cnpq.br/5525206301332584

Maria Helena Mattos Barbosa dos Santos: Universidade Federal de São Carlos, Sorocaba, SP, Brasil.

E-mail: mariahelena@ufscar.br

Link para o currículum Lattes: http://lattes.cnpq.br/3419477918842537

Eliana Cardoso-Leite: Universidade Federal de São Carlos, Sorocaba, SP, Brasil.

E-mail: eliana.leite@ufscar.br

Link para o currículum Lattes: http://lattes.cnpq.br/2186623269243747 